\title{
Atendimento odontológico em tempos de COVID-19: compartilhando boas práticas protetivas e de biossegurança
}

\section{Dental care in COVID-19 times: sharing good protective and biosafety practices}

\author{
Daniela Costa Moraes ${ }^{1}$ (]) \\ Daniela Cristina Diniz Ferreira Galvão² (1) \\ Neiana Carolina Rios Ribeiro ${ }^{3}$ (1) \\ Lisia Mariana Silva de Oliveira 4 (1) \\ Maria Cecília Fonsêca Azoubel ${ }^{5}$ (1) \\ Urbino da Rocha Tunes ${ }^{6}$ (D)
}

\begin{abstract}
1'Autora para correspondência. Escola Bahiana de Medicina e Saúde Pública (Salvador). Bahia, Brasil. danielamoraes@bahiana.edu.br ${ }^{2-6}$ Escola Bahiana de Medicina e Saúde Pública (Salvador). Bahia, Brasil. danielagalvao@bahiana.edu.br, neianacarolina@bahiana.edu.br, lisiaoliveira@bahiana.edu.br, mariaceciliaazoubel@bahiana.edu.br, tunes@bahiana.edu.br
\end{abstract}

RESUMO I INTRODUÇÃO: Durante a pandemia da COVID-19, os cirurgiões-dentistas foram classificados como categoria profissional de alto risco à infecção e transmissão de SARS-Cov2, devido à proximidade da face do paciente bem como pela realização frequente de procedimentos geradores de aerossol. A transmissão desse patógeno durante procedimentos odontológicos pode ocorrer pela inalação de aerossóis/gotículas de indivíduos infectados ou pelo contato direto com membranas mucosas, fluidos orais ou instrumentos e superfícies contaminadas. Ciente dos riscos inerentes ao exercício dessa profissão e diante do cenário mundial, diversas recomendações têm sido sugeridas para cirurgiões-dentistas e estudantes de Odontologia no atendimento aos pacientes. Embora a biossegurança já faça parte da rotina do cirurgião-dentista, o contexto de pandemia pressupõe a necessidade de revisitar os princípios norteadores dessa prática e conhecer as particularidades impostas por um vírus até então desconhecido. OBJETIVO: Este trabalho tem como objetivo propor e discutir medidas de enfrentamento à disseminação do SARS-Cov2 no ambiente odontológico, enfatizando os cuidados necessários para a proteção dos profissionais e pacientes, no contexto da Odontologia no Brasil. MÉTODOS: Para tanto, foi realizada uma compilação de medidas e recomendações baseadas nos principais documentos técnicos publicados nos últimos meses pelas autoridades de saúde. RESULTADOS: As principais recomendações incluem a triagem dos pacientes, distanciamento social, ajustes em equipamentos de proteção individual (EPIs) e o emprego de produtos e técnicas de desinfecção adequados. CONCLUSÃo: Este trabalho apresentou, de forma objetiva e prática, medidas essenciais para atuação odontológica durante a pandemia da COVID-19, ressaltando a provável permanência dessas ações e a importância de adotar medidas rígidas, adequadas e exequíveis.

PALAVRAS-CHAVE: Infecções por coronavírus. Contenção de riscos biológicos. Odontologia.
ABSTRACT | INTRODUCTION: During the COVID-19 pandemic, dentists were classified as a high-risk professional category for SARS-Cov2 infection and transmission, due to the proximity of the patient's face as well as the frequent performance of aerosol-generating procedures. Transmission of this pathogen during dental procedures can occur by inhaling aerosols/droplets from infected individuals or by direct contact with mucous membranes, oral fluids or contaminated instruments and surfaces. Aware of the risks inherent to the exercise of this profession and facing the world scenario, several recommendations have been suggested for dental surgeons and dental students in patient care. Although biosafety is already part of the dentist's routine, the pandemic context presupposes the need to revisit the guiding principles of this practice and to know the particularities imposed by a hitherto unknown virus. OBJECTIVE: This work aims to propose and discuss measures to deal with the spread of SARS-Cov2 in the dental environment, emphasizing the necessary care for the protection of professionals and patients, in the context of Dentistry in Brazil. METHODS: To this end, a compilation of measures and recommendations was made based on the main technical documents published in recent months by the health authorities. RESULTS: The main recommendations include patient screening, social distance, adjustments to personal protective equipment (PPE) and the use of appropriate disinfection products and techniques. CONCLUSION: This work presented, in an objective and practical way, essential measures for dental work during the COVID-19 pandemic, highlighting the probable permanence of these actions and the importance of adopting rigid, adequate and feasible measures

KEYWORDS: Coronavirus infections. Containment of biohazards. dentistry. 


\section{Introdução}

Coronavírus (CoV) compõe uma grande família viral que causa infecções leve a moderadas, semelhantes a um resfriado comum. No final de 2019, um novo Coronavírus foi nomeado como SARS-Cov-2. A doença respiratória aguda causada pelo SARS-CoV-2 foi detectada pela primeira vez em Wuhan, Hubei, China, a partir do aumento do número de casos de pneumonia grave e de etiologia desconhecida, seguida por disseminação e crescimento expressivo do número de casos em outras regiões e países do mundo胒.

Durante a pandemia, os cirurgiões-dentistas foram classificados como categoria de alto risco devido ao potencial de exposição ao coronavírus através de procedimentos que geram aerosso师. O ambiente odontológico parece, de fato, oferecer alto risco de contágio pela exposição à saliva, sangue e aerossol/ gotículas]. A transmissão de SARS-CoV-2 durante procedimentos odontológicos pode, portanto, ocorrer pela inalação de aerossóis/gotículas de indivíduos infectados ou pelo contato direto com membranas mucosas, fluidos orais ou instrumentos e superfícies contaminadas朋.

É sabido de que é responsabilidade dos CDs adotarem medidas de prevenção e controle de infecção para evitar ou reduzir ao máximo a transmissão de microrganismos durante qualquer procedimento odontológico. Ciente desta responsabilidade e dos riscos inerentes à prática dessa profissão e diante do cenário atual, diversas recomendações têm sido sugeridas para cirurgiões-dentistas e estudantes de Odontologia no atendimento aos pacientes脏. As medidas de proteção objetivam evitar ou reduzir procedimentos que produzam gotículas ou aerossóis e inclui a preparação da equipe de saúde bucal, ajustes nos equipamentos de proteção individual (EPIs) e recomendações para limpeza e desinfecção das superfícies].

Considerando a severidade da pandemia de Covid-19 e as mais recentes recomendações dos órgãos e autoridades em saúde, este trabalho foi elaborado com o objetivo de propor e discutir medidas de enfrentamento à disseminação do SarsCov-2 no ambiente odontológico, enfatizando os cuidados necessários para a proteção dos profissionais e pacientes.
Método

Foi realizada uma revisão das principais recomendações para a atuação do cirurgião-dentista durante e após a pandemia da COVID-19. Para tanto, foram considerados artigos e documentos técnicos da área de saúde e/ou odontológica, publicados no ano de 2020. Para a discussão das medidas recomendadas, foram utilizados também artigos nas línguas portuguesa e inglesa, publicados preferencialmente nos últimos 10 anos e disponíveis nas bases de dados Scielo e Pubmed.

\section{Recomendações}

\section{Medidas gerais}

- Aferição da temperatura corporal de todos os pacientes na entrada da instituição e remarcação daqueles que apresentarem temperatura acima de $37,5^{\circ} \mathrm{C}$;

- Redução do número de pacientes a serem atendidos por turno, com intervalos maiores entre os pacientes, a fim de que não haja aglomerações na sala de espera e para que haja tempo para descontaminação do ambiente clínico;

- Execução de maior número de procedimentos (sempre que possível) em um único paciente para otimização do tempo e de custos cos equipamentos de proteção individual;

- Armazenamento dos pertences dos pacientes em um saco plástico ao entrar no ambiente clínico;

- Divulgação ampla que reforce a necessidade do distanciamento social, etiqueta respiratória, uso de máscaras e higienização das mãos;

- Manter toda a equipe atualizada em relação as recomendações e orientações das autoridades sanitárias e órgão competentes.

\section{Equipe profissional}

- Evitar uso de adornos (relógio, brinco, pulseira, corrente, anéis);

- Manter cabelo preso e/ou com uso de gorro;

- Evitar tocar na face (olho, boca e nariz);

- Higienizar as mãos antes e após todos os atendimentos;

- Lavar as mãos com água e sabão por 40 a 60 segundos 10 , ao chegar no trabalho e frequentemente ao longo do horário de serviço; 
- Realizar a técnica correta de lavagem das mãos e retirada dos Equipamentos de Proteção Individual (EPIs);

- Dinamizar o atendimento para reduzir o volume de pacientes em salas de espera.

\section{Estrutura física}

- Realizar marcações de distanciamento de um metro e meio na entrada de pacientes para evitar aglomerações nas filas de atendimento;

- Realizar bloqueio parcial das cadeiras destinadas aos pacientes na recepção, respeitando a distância mínima exigida;

- Nas áreas de convívio comum, manter as portas abertas para circulação de ar e redução do manuseio;

- Disponibilizar reservatórios de álcool em gel a 70\% em todos os ambientes de circulação de pessoas;

- Nos ambulatórios e consultórios, manter as janelas e portas abertas ao final de cada turno, por no mínimo uma hora 11, para que haja circulação de ar;

- Garantir o funcionamento do sistema de exaustão dos ares condicionados e fazer manutenção periódica dos equipamentos;

- Instalar aparelho para renovação do ar (sistema portátil de filtração do ar), principalmente em salas que não possuem janelas.

\section{Agendamentos}

Os profissionais da recepção são os primeiros a entrarem em contato com o paciente para agendamento, bem como no dia do atendimento; desta forma, funcionarão como "porta-vozes" das informações importantes que envolvem as condutas durante e após a pandemia da COVID-19:

- Por telefone, antes do agendamento, perguntar ao paciente se ele:

- Teve sintomas de gripe, perda de olfato ou paladar, mesmo que leves, nos últimos 14 dias;

- Teve alguns dos seguintes sintomas, mesmo que rápidos: diarreia, febre, fadiga intensa ou dores no corpo nos últimos 14 dias;

- Teve contato com pessoas com sintomas de gripe ou que testaram positivo para a COVID-19 nos últimos 14 dias.
- Em caso de resposta afirmativa para algumas destas perguntas citadas, informar ao paciente que seu atendimento precisará ser adiado;

- Orientar o paciente de que não será permitida a entrada de acompanhantes no dia do atendimento, a exceção de pacientes menores de idade, idosos, ou quando for uma solicitação do cirurgião-dentista, diante da necessidade clínica do paciente (exemplo: pacientes especiais, procedimentos cirúrgicos);

- Exigir que os pacientes venham para o atendimento usando máscaras'?

\section{Procedimentos de sala de espera}

Os profissionais da recepção devem:

- Acolher o paciente para que ele se sinta confortável e seguro no ambiente clínico;

- Confirmar presencialmente as perguntas feitas por telefone assim que o paciente entrar na clínica/consultório;

- Utilizar obrigatoriamente a máscara (pode ser de tecido) durante todo o período que estiverem prestando atendimento à população;

- Realizar frequentemente a higiene das mãos com água e sabão líquido ou preparação alcoólica a 70\%;

- Fiscalizar o uso de máscara e o distanciamento de no mínimo 1,5 metros entre os pacientes que estão aguardando $o$ atendimento e/ou agendamento;

- Não manipular pertences dos pacientes como carteiras, cartões e documentos de identificação;

- Caso seja necessária a efetuação de pagamentos, dar preferência a pagamentos com cartão e higienizar adequadamente a máquina com álcool a $70 \%$ antes e após os pagamentos.

\section{Recomendações para o atendimento clínico}

Durante e após pandemia de COVID-19, alguns cuidados adicionais devem ser adotados para diminuir o risco de contaminação no ambiente clínico odontológico. Alguns são descritos a seguir e outros estão evidenciados na Figura 1.

- Ao chamar os pacientes, orientá-los a higienizarem adequadamente as mãos e reforçar sobre a guarda dos pertences no saco plástico disponibilizado para esta finalidade. Apenas a máscara deve ser mantida com o paciente e removida no momento do atendimento; 
- Utilizar preferencialmente a sucção de alta potência (bomba à vácuo);

- Lavar adequadamente as mãos com água e sabão antes e após cada atendimento;

- Evitar o uso de computadores portáteis e celulares no ambiente clínico, tendo em vista o risco de se tornarem vetores de contaminação.

Figura 1. Cuidados específicos com o paciente durante o atendimento odontológico

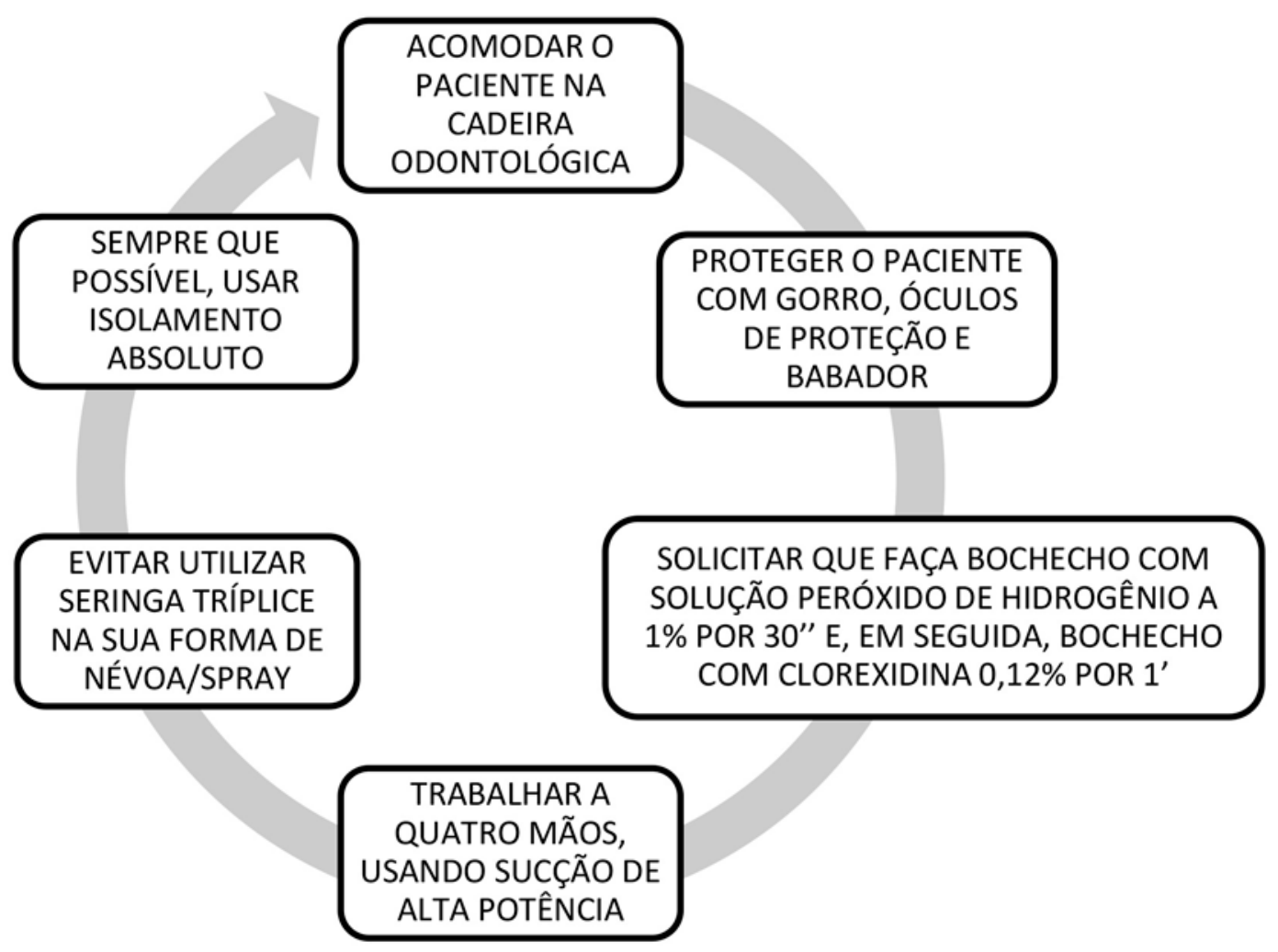

Fonte: Adaptado da Nota técnica-Anvisa n.05/2020.

\section{Recomendações de biossegurança}

Frente à pandemia e a grande transmissibilidade do SARS-Cov2, alguns equipamentos de proteção individual passaram a ser exigidos pelas autoridades sanitárias e foram adicionados aos usuais EPIs do cirurgião dentista e corpo técnico. A descrição completa dos EPIs e modo de utilização está sintetizada no Quadro 1. 


\begin{tabular}{|c|c|c|c|}
\hline EPI & Para que usa & Quando usa & Quando descarta \\
\hline Gorro & $\begin{array}{l}\text { Proteção de cabelos e } \\
\text { couro cabeludo }\end{array}$ & $\begin{array}{l}\text { Desde o momento que } \\
\text { entrar no ambiente clínico }\end{array}$ & $\begin{array}{l}\text { Descartar após um turno de } \\
\text { trabalho }\end{array}$ \\
\hline $\begin{array}{l}\text { Máscara } \\
\text { cirúrgica*1 }^{*}\end{array}$ & $\begin{array}{l}\text { Proteção da região de } \\
\text { boca e nariz }\end{array}$ & $\begin{array}{l}\text { No CME e em } \\
\text { procedimentos que não } \\
\text { gerem aerossol }\end{array}$ & $\begin{array}{l}\text { Utilizar uma por paciente. } \mathrm{Na} \\
\mathrm{CME} \text {, substituir quando estiver } \\
\text { úmida ou suja }\end{array}$ \\
\hline $\begin{array}{l}\text { Protetor } \\
\text { respiratório } \\
\text { (Máscara } \\
\text { N95/PFF2 ou } \\
\text { equivalente) }\end{array}$ & $\begin{array}{l}\text { Proteção de região de } \\
\text { nariz e boca }\end{array}$ & $\begin{array}{l}\text { Durante o atendimento } \\
\text { odontológico que gere } \\
\text { aerossol }\end{array}$ & $\begin{array}{l}\text { Trocar a cada } 7 \text { dias, se uso } \\
\text { conjunto com o protetor } \\
\text { facial }^{\star 2}\end{array}$ \\
\hline $\begin{array}{l}\text { Avental } \\
\text { descartável }\end{array}$ & $\begin{array}{l}\text { Proteção do tronco e dos } \\
\text { braços }\end{array}$ & $\begin{array}{l}\text { Durante o atendimento } \\
\text { odontológico não gerador } \\
\text { de aerossol }\end{array}$ & Utilizar um por paciente \\
\hline $\begin{array}{l}\text { Avental } \\
\text { impermeável }\end{array}$ & $\begin{array}{l}\text { Proteção do tronco e dos } \\
\text { braços }\end{array}$ & $\begin{array}{l}\text { Durante o atendimento } \\
\text { odontológico que gere } \\
\text { aerossol }\end{array}$ & Utilizar um por paciente \\
\hline $\begin{array}{l}\text { Óculos de } \\
\text { proteção*3 }\end{array}$ & Proteção dos olhos & $\begin{array}{l}\text { Durante todo o turno de } \\
\text { trabalho no ambiente } \\
\text { clínico }\end{array}$ & $\begin{array}{l}\text { Não é descartável, mas deve } \\
\text { ser higienizado após cada } \\
\text { atendimento }\end{array}$ \\
\hline Protetor facial & Proteção do rosto & $\begin{array}{l}\text { Durante o atendimento } \\
\text { odontológico }\end{array}$ & $\begin{array}{l}\text { Não é descartável. Higienizar a } \\
\text { cada troca de paciente e } \\
\text { descontaminar ao final de } \\
\text { cada } \text { dia }^{* 4}\end{array}$ \\
\hline $\begin{array}{l}\text { Luvas de } \\
\text { procedimento }\end{array}$ & Proteção das mãos & $\begin{array}{l}\text { Durante o atendimento } \\
\text { odontológico }\end{array}$ & Trocar a cada paciente \\
\hline
\end{tabular}

Fonte: adaptado do Manual de boas práticas em biossegurança para ambientes odontológicos. CFO, 2020.

Além disso, seguem elencadas outras recomendações atribuídas à equipe de saúde bucal:

a) Cirurgiões-dentistas

- Não entrar com pertences pessoais como bolsas, pastas e mochilas no ambiente de atendimento odontológico (consultório ou ambulatório);

- Utilizar pijama cirúrgico e sapatos fechados de uso exclusivo para o ambiente clínico;

- Se paramentar adequadamente com avental, gorro, luva, equipamento de proteção respiratória (EPR) N95/ PFF2 ou equivalente, e protetor facial todas as vezes que forem necessárias intervenções clínicas que gerem aerossol (PGAs);

- Em PGAs, o avental impermeável deve apresentar gramatura mínima de 30g/m2国 e ser trocado a cada paciente atendido;

- Em caso de avaliações e exames, os quais não geram aerossol, usar aventais descartáveis simples, e trocá-los a cada paciente;

- Realizar a desparamentação de forma cuidadosa e sistemática, com constante higienização das mãos, como descrito na figura 2;

- Descontaminar o protetor facial, adequadamente, com água e sabão neutro entre uma avaliação e outra e, ao final do dia, deixar imerso por 1 hora em hipoclorito de sódio a 1\%. 
b) Técnicas e auxiliares de saúde bucal

- Não levar pertences pessoais como bolsas e mochilas para o ambiente clínico odontológico, bem como, não manipular aparelhos eletrônicos nestes ambientes;

- Realizar sistematicamente a higiene das mãos com água e sabão ou preparação alcoólica a 70\%;

- Utilizar pijama cirúrgico e sapatos fechados de uso exclusivo para o ambiente clínico;

- Utilizar EPIs adequados e similares aos do cirurgião-dentista no auxílio direto de procedimentos;

- Realizar a desparamentação de forma cuidadosa e sistemática, com constante higienização das mãos, como descrito na figura 2;

- Preencher o reservatório de água das cadeiras odontológicas com solução de hipoclorito de sódio a 1\% (diluição de 0,6 mL de para 1 litro de água) $\rrbracket^{\sqrt{1}}$ e esvaziar ao final de cada dia;

- Realizar a descontaminação das mangueiras da cadeira odontológica com hipoclorito de sódio a 1\% ou outras soluções desinfetantes recomendadas;

- Se paramentar adequadamente com avental descartável, máscara cirúrgica, gorro e luvas de borracha de cano longo para realizar a descontaminação dos materiais contaminados.

Figura 2. Instrução para retirada de EPIs

\section{DESPARAMENTAÇÃO}

\section{EQUIPAMENTOS DE PROTEÇÃOINDIVIDUAL (EPI) UTILIZADOS EM PROCEDIMENTOS GERADORES DEAEROSSÓIS}

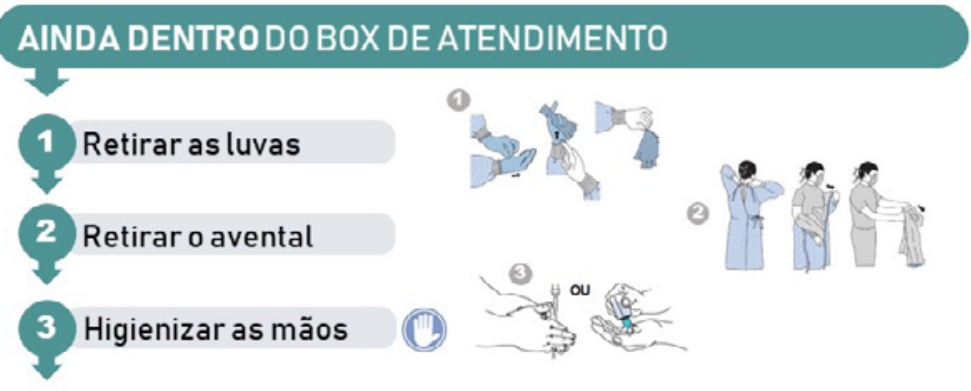

\section{SAIR DO BOX DE ATENDIMENTO}

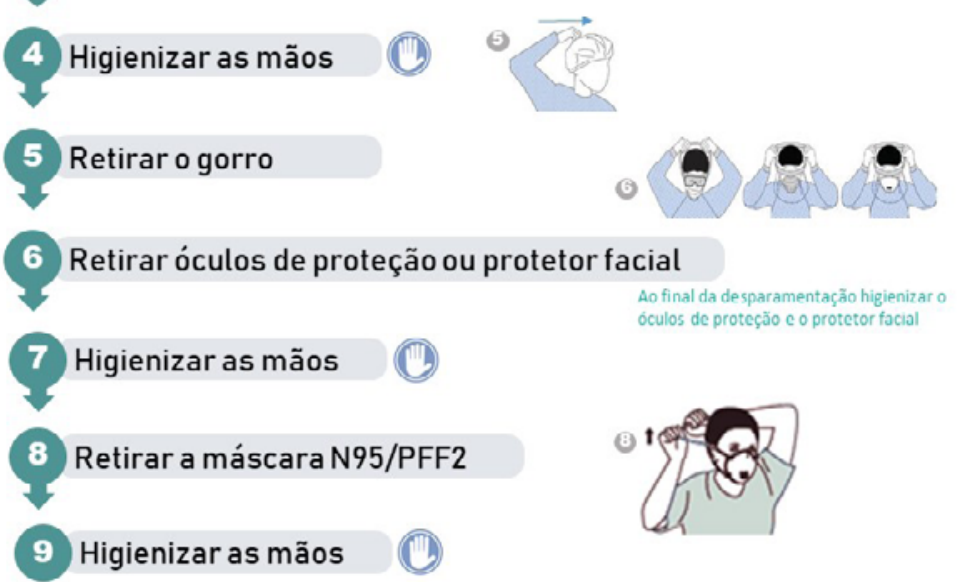

Fonte: Nota técnica GVIMS/GGTES/ANVISA Nº 04/2020. 


\section{Recomendações para desinfecção do ambiente clínico odontológico}

Durante a pandemia da COVID-19, algumas recomendações de desinfecção do ambiente odontológico também foram reforçadas.

- Usar gorro, máscara e luva de borracha para fazer a higienização do consultório;

- Realizar a limpeza dos equipamentos ao final dos atendimentos com água e sabão sob fricção e, após, utilizando álcool líquido a 70\% (por fricção) e na ordem a seguir: refletor, braço da cadeira odontológica, cadeira odontológica, mocho e superfícies auxiliares, inclusive equipamentos de mão (seringa tríplice e unidades de sucção). A cuspideira deve ser descontaminada com hipoclorito de sódio a 1\%;

- Proteger o teclado dos computadores dos ambulatórios com filme PVC e higienizá-los com álcool a 70\%;

- Higienizar regularmente maçanetas de portas com álcool a 70\%;

- Realizar a limpeza do ambiente clínico e salas de espera usando álcool a 70\% para superfícies e hipoclorito de sódio a 1\% para limpeza do piso (importante fazer a limpeza prévia com água e sabão);

- A desinfecção das áreas externas (portão, corrimão e cadeiras da recepção) pode ser realizada com pulverizador contendo solução a 0,3\% de ácido peracético (diluição $3 \mathrm{~mL}$ de ácido peracético 15\% em $1 \mathrm{~L}$ de água) ou solução de quaternário de amônio de $5^{a}$ geração (Ex.: cloreto de benzalcônio 0.05\%)

O quadro 2 complementa os itens anteriores e contém a descrição dos principais produtos utilizados para esta finalidade.

Quadro 2. Desinfetantes para uso em ambiente odontológico

\begin{tabular}{|c|c|c|c|c|}
\hline Produto & Concentração & Vantagens & Desvantagens & Uso \\
\hline Álcool & $\begin{array}{l}\text { Ação germicida a } \\
70 \%\end{array}$ & $\begin{array}{l}\text { Fácil aplicação, ação } \\
\text { rápida, compativel com } \\
\text { artigos metálicos e de } \\
\text { vidro (ex: superfícies e } \\
\text { tubetes anestésicos) }\end{array}$ & $\begin{array}{l}\text { Volátil, inativado por } \\
\text { matéria orgânica, } \\
\text { inflamável, opacifica } \\
\text { acrílico, resseca plásticos } \\
\text { e pode danificar lentes de } \\
\text { equipamentos ópticos }\end{array}$ & $\begin{array}{l}\text { Por fricção em } \\
\text { equipamentos } \\
\text { odontológicos, } \\
\text { peças de mão e } \\
\text { computadores }\end{array}$ \\
\hline $\begin{array}{l}\text { Ácido } \\
\text { Peracético }\end{array}$ & $0,2 \%$ & $\begin{array}{l}\text { Não forma resíduos } \\
\text { tóxicos, efetivo na } \\
\text { presença de matéria } \\
\text { orgânica, rápida ação } \\
\text { em baixa temperatura }\end{array}$ & $\begin{array}{l}\text { Instável quando diluído e } \\
\text { corrosivo para alguns } \\
\text { tipos de metais }\end{array}$ & $\begin{array}{l}\text { Desinfecção de } \\
\text { superfícies, } \\
\text { mangueiras de ar } \\
\text { e de água }\end{array}$ \\
\hline $\begin{array}{l}\text { Hipoclorito de } \\
\text { Sódio }\end{array}$ & $1 \%$ & $\begin{array}{l}\text { Ação rápida, ideal para } \\
\text { materiais termo } \\
\text { sensíveis }\end{array}$ & $\begin{array}{l}\text { Instável, corrosivo, } \\
\text { inativado na presença de } \\
\text { matéria orgânica }\end{array}$ & $\begin{array}{l}\text { Por fricção em } \\
\text { pisos e cuspideiras }\end{array}$ \\
\hline $\begin{array}{l}\text { Quaternário } \\
\text { de amônio } 5^{\text {a }} \\
\text { geração }\end{array}$ & $\begin{array}{l}\text { Cloreto de } \\
\text { Benzalcônio } \\
0.05 \%\end{array}$ & $\begin{array}{l}\text { Não é corrosivo, tem } \\
\text { baixo custo }\end{array}$ & $\begin{array}{l}\text { Pode causar irritação da } \\
\text { pele e das vias } \\
\text { respiratórias, é inativado } \\
\text { por matéria orgânica }\end{array}$ & $\begin{array}{l}\text { Pulverização em } \\
\text { áreas externas } \\
\text { (portão, corrimão } \\
\text { e cadeiras da } \\
\text { recepção) }\end{array}$ \\
\hline
\end{tabular}

Fonte: adaptado do Manual de boas práticas em biossegurança para ambientes odontológicos. CFO, 2020 e Nota técnica- Anvisa n.34/2020. 


\section{Discussão}

A pandemia da COVID-19 veio como um grande desafio de adaptação para realização da prática odontológica. Procedimentos comuns no consultório odontológico geram grande quantidade de gotículas e aerossol, aumentando muito o risco de contaminação do CD e equipe. Estudos mostram que a atividade odontológica gera um raio de contaminação de até quase 2 metros' tal para redução do risco de infecção pela equipe de saúde bucal胞. Sotiriou et al. (2006) mediram as partículas liberadas no ambiente odontológico e sugeriram que os procedimentos de perfuração dentária geram aerossol proveniente da saliva e dos produtos da perfuração, produzindo partículas pequenas o suficiente para penetrar profundamente nos pulmões

Visando prover diretrizes para a atuação destes profissionais, autoridades sanitárias nacionais (ANVISA) 10 国 e mundiais (OMS) tos técnicos que orientam sobre o exercício seguro das profissões da saúde, incluindo a Odontologia. E além desses, outros órgãos de representação de classe, como Conselhos Regionais de Odontologia $(\mathrm{CRO})^{21}$ e o Conselho Federal de Odontologia (CFO) ${ }^{22}$ emitiram documentos norteadores.

Alguns desses documentos trazem informações específicas sobre ajustes quanto ao uso de EPIs, a exemplo da nota técnica da ANVISA 04/2020, que passa a exigir o uso de avental impermeável de gramatura mínima de $30 \mathrm{~g} / \mathrm{m} 2$ e protetor respiratório N95/PFF2 ou equivalente para procedimentos geradores de aerossolip. A regulamentação do CFO (2020) reforçou a necessidade do uso de protetor facial e do protetor respiratório, mas pontuou que, devido à escassez de EPIs, se faz necessária a adaptação à realidade de cada serviço, respeitando-se as normas vigentes propostas pela Comissão de Controle de Infecção Hospitalar (CClH)22. Assim, o descarte ou armazenamento do protetor respiratório devem ser feitos de acordo com as normas do serviço de saúde em consonância com a $\mathrm{CCIH}$ de cada serviço. Caso a $\mathrm{CCIH}$ do serviço recomende o armazenamento das máscaras N95/PFF2 ou equivalentes, preconiza-se o uso de embalagens individuais não herméticas, de forma a permitir a saída de umidade (por exemplo, embalagem plástica perfurada). Não é recomendável o uso de embalagem de papel ou de outro material que absorva umidade ou sirva de substrato para a proliferação de patógenos²
As máscaras de tecido se tornaram muito comuns no cenário da pandemia. Elas não são reconhecidas como EPI pela OMS 24 , e por este motivo, não devem ser utilizadas pelos profissionais da saúde; no entanto, elas podem ser utilizadas pelos colaboradores técnico-administrativos e pelos pacientes desde o momento que entrarem na recepção dos serviços de Odontologia. Elas são eficazes para situações sociais em que há distanciamento maior que um metro e são recomendadas para uso diário da população円.

Os produtos e protocolos de desinfecção também são bastante discutidos nos documentos técnicos. No Brasil, o órgão que fiscaliza a eficácia e segurança desses produtos é a ANVISA, a qual dispõe de uma lista de agentes químicos regulamentados para uso em ambiente clínico 1 . É muito importante que todas as normas técnicas e manuais publicados no Brasil estejam em total consonância com as recomendações da ANVISA.

No que se refere ao risco de transmissão de COVID-19, a retirada sistemática e adequada dos EPIs tem assumido destaque nos principais documentos técnicos. A literatura já demonstrou um alto risco de infecção do

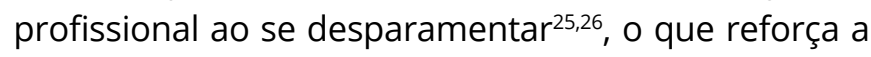
necessidade de estratégias eficazes de remoção dos EPIs e do treinamento contínuo do CD e técnicos/auxiliares de saúde bucal para execução desta atividade.

Os documentos que já foram publicados pelos diversos órgãos sanitários e conselhos de classe, embora sigam as normas nacionais, foram escritos baseados na experiência de outros países que foram acometidos pela pandemia anteriormente ao Brasil e, assim, existem divergências entre eles em alguns aspectos. Por esse motivo, surgem dúvidas de quais seriam as principais medidas a serem tomadas e como adequar estas normas técnicas à realidade da Odontologia brasileira em suas diferentes regiões, tornando-as exequíveis no cenário socioeconômico de um país com realidades privadas e públicas absolutamente distintas.

O aumento do uso de EPIs por uma gama maior de profissionais gerou uma crise de escassez desses materiais, além do aumento expressivo do custo destes equipamentos. O uso racional dos EPIs é uma preocupação mundial, documentada pela OMS súbito da procura em detrimento da baixa demanda, além das preocupações vinculadas à sustentabilidade ambiental, no que se refere ao descarte adequado destes equipamentos. Devido ao alto risco ocupacional, os 
profissionais da Odontologia provavelmente estarão entre os principais consumidores destes produtos.

Vale ressaltar que a Odontologia brasileira vem sofrendo há alguns meses por conta da impossibilidade de atuação profissional em procedimentos eletivos, consequente do necessário isolamento social para contenção da pandemia. Cientes de que as novas recomendações de desinfecção e biossegurança irão acarretar em custos altos e imprevistos ao exercício da Odontologia, é imperativo que os órgãos sanitários sejam sensíveis à conjuntura socioeconômica dessa classe, que tenta se reerguer, e busque estratégias e recursos adequados, mas que possam ser acessíveis e aplicáveis em todos os âmbitos onde a Odontologia é exercida, seja ele privado ou público; afinal, a biossegurança é única e para todos.

Entende-se que as mudanças impostas pela pandemia da COVID-19 servirão para aumentar a rigidez com a biossegurança, que é de elevada importância e que por alguns anos tem sido negligenciada na Odontologia ${ }^{28}$. Proteger os profissionais e os pacientes é crucial para cessar a disseminação de microrganismos causadores de doenças. Este trabalho apresentou, de forma prática, medidas essenciais para atuação odontológica durante a após a pandemia da COVID-19 e ressaltou a importância de se adotar medidas coerentes e exequíveis. Acredita-se que, tendo o bom senso como aliado e a união de forças entre a classe odontológica e os órgãos sanitários, é possível se fazer uma Odontologia de qualidade mesmo diante de um cenário nunca antes vivido.

\section{Contribuições dos autores}

Moraes DC participou da concepção, busca literária, redação e revisão do artigo científico; Galvão DCDF, Ribeiro NCR, Oliveira LMS participaram da concepção, busca literária e redação do artigo; Azoubel MCF participou da concepção, busca literária, redação e revisão crítica do artigo científico; Tunes UR participou da revisão do artigo e aprovação final da versão a ser publicada.

\section{Conflitos de interesses}

Nenhum conflito financeiro, legal ou político envolvendo terceiros (governo, empresas e fundações privadas, etc.) foi declarado para nenhum aspecto do trabalho submetido (incluindo, mas não se limitando a subvenções e financiamentos, participação em conselho consultivo, desenho de estudo, preparação de manuscrito, análise estatística, etc.).

\section{Referências}

1. Franco JB, Camargo AR, Peres MPSM. Cuidados Odontológicos na era do COVID-19: recomendações para procedimentos odontológicos e profissionais. Rev Assoc Paul Cir Dent. 2020;74(1):18-21.

2. Meng L, Hua F, Bian Z. Coronavirus Disease 2019 (COVID-19): Emerging and Future Challenges for Dental and Oral Medicine. Journal of Dental Research. 2020;99(5):481-487. doi: 10.1177/0022034520914246

3. Peng X, Xu X, Li Y, Cheng L, Zhou X, Ren B. Transmission routes of 2019-nCoV and controls in dental practice. International Journal of Oral Science 2020;12:9. doi: 10.1038/s41368-020-0075-9

4. Spagnuolo G, De Vito D, Rengo S, Tatullo M. COVID-19 Outbreak: An Overview on Dentistry. Int J Environ Res Public Health. 2020;17(6):2094. doi: 10.3390/ijerph17062094

5. Gamio I. The workers who face the greatest coronavirus risk. The New York Times [Internet]. 2020 [acesso 2020 jun]. Disponível em: https://www.nytimes.com/interactive/2020/03/15/business/ economy/coronavirus-worker-risk.html

6. Izzetti R, Nisi M, Gabriele M, Graziani F. COVID-19 Transmission in Dental Practice: Brief Review of Preventive Measures in Italy. Journal of Dental Research. 2020. doi: 10.1177/0022034520920580

7. Alharbi A, Alharbi S, Alharbi S. Guidelines for Dental Care Provision During the COVID-19 Pandemic. Saudi Dent J. 2020;32(4):181-186. doi: 10.1016/j.sdentj.2020.04.001

8. Barabari P, Moharamzadeh K. Novel Coronavirus (COVID-19) and Dentistry-A Comprehensive Review of Literature. Dent J. 2020;8(2):E53. doi: 10.3390/dj8020053

9. Brasil. Decreto 32.478, de 05 de junho de 2020. Altera dispositivo do Decreto $n^{\circ} 32.461$, de 01 de junho de 2020, na forma que indica. Diário Oficial do Município. 2020 jun 05 [acesso em 2020 jun]. Disponível em: http://www.transparencia.salvador. ba.gov.br/documentacao/covid19/legislacaoMunicipal/D32478. pdf

10. Nota técnica GVIMS/GGTES/ANVISA Nº 04/2020. Orientações para serviços de saúde: medidas de prevenção e controle que devem ser adotadas durante a assistência aos casos suspeitos ou confirmados de infecção pelo novo coronavírus (sars-cov-2). (Atualizada em 31/03/2020). Disponível em: http://portal.anvisa. gov.br/documents/33852/271858/Nota+T\%C3\%A9cnica+n+042020+GVIMS-GGTES-ANVISA/ab598660-3de4-4f14-8e6fb9341c196b28

11. Ricci WA. Guia odontológico para atendimento durante pandemia COVID-19. Belo Horizonte, MG: SOBRAPE; 2020. 
12. Decreto 32.357, de 20 de abril de 2020. Define medidas complementares para enfrentamento da pandemia decorrente do coronavirus. 2020 [acesso 2020 mai.]. Disponível em: https:// leismunicipais.com.br/a/ba/s/salvador/decreto/2020/3236/32357/ decreto-n-32357-2020-define-medidas-complementares-paraenfrentamento-da-pandemia-decorrente-do-coronavirus

13. Jorge EF, Azevedo V, Fernandes A, Araújo M, Brito L, Ferraz F et al. Face Shield for Life 3D: produção colaborativa, usando a comunidade de makers dos protetores faciais padrão RC3 para os profissionais de saúde em Salvador. Cadernos de Prospecção. 2020;13(2):513-25. doi: 10.9771/cp.v13i2.COVID-19.36174

14. Nota técnica $n^{\circ} 34 / 2020$. Ementa: Recomendações e alertas sobre procedimentos de desinfecção em locais públicos realizados durante a pandemia da COVID-19. Disponível em: http://portal.anvisa.gov.br/documents/219201/4340788/SEI_ ANVISA+-+0976782+-+Nota+T\%C3\%A9cnica.pdf/1cdd5e2f-fda14e55-aaa3-8de2d7bb447c

15. Discacciati JAC, Sander HH, Castilho LS, Resende VLS. Verificação da dispersão de respingos durante o trabalho do cirurgião-dentista. Rev Panam Salud Publ. 1998;3(2):84-7.

16. Scannavino FLF, Santos-Pinto L, Hernandes AC. Sucção de alta potência no controle das partículas emitidas pelo sistema de abrasão a ar em consultório odontológico. Rev Bras Saúde Ocup. 2006;31(113):49-56. doi: 10.1590/\$0303-76572006000100006

17. Nejatidanesh F, Khosravi Z, Goroohi H, Badrian H, Savabi O. Risk of Contamination of Different Areas of Dentist's Face During Dental Practices. Int J Prev Med. 2013;4(5):611-615.

18. Sotiriou M, Ferguson SF, Davey M, Wolfson JM, Demokritou $\mathrm{P}$, Lawrence J et al. Measurement of particle concentrations in a dental office. Environ Monit Assess 2008;137(1-3):351-361. doi: 10.1007/s10661-007-9770-7

19. Nota Técnica Nº5/2020 GVIMS/GGTES/ANVISA. Orientações para serviços de saúde: medidas de prevenção e controle que devem ser adotadas durante a assistência aos casos suspeitos ou confirmados de infecção pelo novo coronavírus (sars-cov-2). (Atualizada em 08/05/2020). Disponível em: https://www20.anvisa. gov.br/segurancadopaciente/index.php/alertas/item/nota-tecnicagvims-ggtes-anvisa-n-05-2020

20. World Health Organization. Infection prevention and control during health care when COVID-19 is suspected [Internet]. 2020. WHO reference number: WHO/2019-nCoV/IPC/2020.3

21. Conselho Regional de Odontologia da Bahia. Sugestões sobre o retorno ao trabalho nos consultórios odontológicos da rede privada na cidade de Salvador [Internet]. 2020 [Acesso 2020 abr.]. Disponível em: www.croba.org.br

22. Conselho Regional de Odontologia. Recomendações para Atendimentos Odontológicos em Tempos de Covid-19 [Internet]. 2020 [acesso em 2020 abr.]. Disponível em: http://website.cfo.org. br/plano-de-prevencao-cfo-anuncia-novas-medidas-para-auxiliarna-contencao-do-coronavirus/
23. Agência Nacional de Vigilância Sanitária. Cartilha de Proteção Respiratória contra Agentes Biológicos para Trabalhadores de Saúde [Internet]. 2006 [acesso 2020 abr.]. Disponível em: http://www2.ebserh.gov.br/documents/214604/816023/ Cartilha+de+Proteção+Respiratória+contra+Agentes+Biológicos+para+Trabalhadores+de+Saúde.pdf/58075f57-e0e2-4ec5-aa96-743d142642f1

24. World Health Organization. Advice on the use of masks in the context of COVID-19 [Internet]. 2020. Disponível em: https:// www.who.int/publications/i/item/advice-on-the-use-of-masks-thecommunity-during-home-care-and-in-health-care-settings-in-thecontext-of-the-novel-coronavirus-(2019-ncov)-outbreak

25. Guo YP, Li Y, Wong PLH. Environment and body contamination: a comparison of two different removal methods in three types of personal protective clothing. Am J Infect Control. 2014;42(4):e39-e45. doi: 10.1016/j.ajic.2013.12.021

26. Tomas ME, Kundrapu S, Thota P, Sunkesula VCK, Cadnum $J \mathrm{~L}$, Mana TSC et al. Contamination of the skin and clothing of healthcare personnel during removal of personal protective equipment. JAMA Intern Med. 2015;175(12):1904-1910. doi: 10.1001/jamainternmed.2015.4535

27. World Health Organization. Rational use of personal protective equipment for coronavirus disease (COVID-19) and considerations during severe shortages [Internet]. 2020. Disponível em: https:// www.who.int/publications/i/item/rational-use-of-personalprotective-equipment-for-coronavirus-disease-(covid-19)-andconsiderations-during-severe-shortages

28. Matsuda JK, Grinbaum RS, Davidowicz H. The assessment of infection control in dental practices in the municipality of São Paulo. Braz J Infect Dis. 2011;15(1):45-51. doi: 10.1590/S141386702011000100009 